\title{
Elevating Form and Elevating Modulation (2015)
}

\section{[https://doi.org/ 10.1017/S026114301400066X]}

\section{Dai Griffiths, Oxford Brookes University}

The elevating modulation is a familiar element of the pop performance and recording, to the academic study of which this paper makes a contribution. 1 The modulation can informally be defined by three aspects - it is found usually towards the end of a track, is usually upwards in direction, and is usually upwards by a semi-tone or tone - but in such attributes 'usually' does its usual hard work, and this paper will engage with those three details, among others. I shall introduce the term 'elevating' modulation, suggesting that it is best used alongside 'elevating' form. My approach is bottom-up, starting from many simple examples in order to present a four-part schema. My repertory is deliberately wide-ranging, incorporating classical music, children's music, a comic song, an anthemic song, as well as examples from jazz, rock and pop; by date, the examples of elevating modulation traverse a period between 1944 and 2011. The number of examples allies the paper more with the harmony textbook than the analytical study, and I shall further explain that dichotomy and emphasis presently. My examples are indeed limited largely to modulations upwards by a semitone and by a tone, but occasional reference will be made to other transpositional levels. First, however, I'd like to step outside the popular domain2 and discuss an example of modulation in Mozart, as mediated by the music theorist Carl Schachter. This discussion will introduce two themes: an example of a modulation which returns to the original key, and a critical attitude towards taking a schematic approach to the modulation.

As the culmination of an essay on modulation, Schachter analyses 'Voi che sapete' from Mozart's The Marriage of Figaro, an arietta in $\mathrm{Bb}$ major whose 'problem centers on measures 37-52, which contain a fully tonicized Ab major (measures 37-44) including a cadential bass and melodic closure on Ab' (Schachter 1999, p. 152). Schachter dismisses two interpretations of the Ab passage. To the suggestion that $\mathrm{Ab}$ is dominant of $\mathrm{Db}$ : 'Where is the D flat major to which this Ab relates as a V?' (p. 153), while 'To think of the Ab major as IV of IV also seems wrong to me: Eb as a tonic occurs nowhere in the Arietta' (p. 153). Arnold Schoenberg is the chief culprit: the first interpretation is his bMD, the second his SDSD (Schoenberg 1969, p. 69). Schachter issues summary judgement: 'In my view the Ab major is neither V of bIII nor IV of IV. In any case, the function of a key area can only be understood in relation to context and not on the basis of some abstract schema' (p.153). This sentence also encapsulates a principle: 'relation to context' beats 'some abstract schema'. Schachter then presents a dazzling reading of the song, in which the key passage is perhaps this one: 
Schenker's notion of Auskomponierung allows him to find meaningful larger contexts for chords (including tonicized chords) that are not under the control of an immediately perceptible local tonic. He can do this because he recognizes counterpoint as a shaping force in composition, a force that can give rise to successions of chords and, indeed, to "keys" (p. 155).

Counterpoint in Composition. However, the more immediate problem with the dismissed explanations is not simply that they posit 'some abstract schema' but incorrect abstract schemata. Schachter provides an accurate alternative, elegantly integrating harmony and counterpoint:

It would be far preferable to call this $\mathrm{Ab}$ the flat mediant of the dominant, for the key area does in fact crystallize around the lowered third of a broken F major chord. The Ab, however, is not a scale step in the key of $\mathrm{F}$; for the impression of $\mathrm{F}$ as a tonic begins to disappear at measure 36. It is the chord of $\mathrm{F}$ minor, and not the key, that provides the basis for this strain, rather like a sonata development where dominant harmony continues to direct the musical motion after the dominant key has finished for good. (p. 153)

Put more simply, and only in harmonic terms, the music is firmly in $\mathrm{F}$ major from bar 21 , tonicizing $\mathrm{C}$ major as $\mathrm{V}$ of $\mathrm{F}$ eight bars later (28), then landing on C major as half-cadence twice over the next two four-bar phrases (32 and 36); a small but important and expressive touch of $\mathrm{F}$ minor mixture at bar 35 foreshadows and eases in the shift to A flat at bar 37. A flat major is thus bVI of V (C), which is in turn bIII of F (as Schachter says), and in turn yet again bVII of Bb. Thus, bVI of $\mathrm{V}$ of $\mathrm{V}$ of I is the unwieldy summary of those stages.

The problem passage done with, Mozart's arietta returns by a more circuitous route to B flat major as home key, and the principle that modulation is followed by return to a home key is fundamental in this style. However, Harald Krebs (1981) for one discusses examples of musical works of the early nineteenth-century that begin in one key and end in another, and my topic, the elevating form and elevating modulation, belongs firmly in Krebs's camp. My focus is on the passage of modulation within the example, and thus concerned with the excerpt, at the risk of doing harm to the overall context of that excerpt, context being Schachter's proper analytical insistence. My paper tends towards what Thomas Christensen calls 'practical or regulative theory', or the harmony textbook, rather than the single-work analysis but, of course as Christensen reminds us, 'analysis functions as a dialectical counterpart to theory. Analysis constitutes the detailed study of musical pieces from which theories may be inductively formulated, while at the same time serving to test the empirical validity and application of any theory.' (Christensen 2001, vol. 13, p. 494) One also hopes for the excerpt to be Matthew Arnold's touchstone (Arnold, 1970, pp. 347-9), a locus classicus suggestive of other examples. Using Schachter's terms, the paper thus defends the establishing of 'some abstract 
schema', while not for a moment denying the importance of immediate context: indeed, it could be claimed that if a track including an elevation is no good, the elevation will not be enough to rescue it.

Furthermore, characterising the function of the elevating modulation is a challenge: what is its purpose? Adam Ricci (Ricci 2000, p. 130) draws our attention to Robert Bailey's identification of an 'expressive' use of tonality in the music of Richard Wagner, but Bailey's other term, the 'associative' use of tonality, adds to the problem (Bailey 1977, p. 51).3 Whatever the effect of its presentation, the elevating modulation as harmonic device must express something musically, and the examples that follow will traverse a range from the modulation's acting as formal marker to high drama. But the elevating modulation also brings with it an associative sense of cliché. Consider recording artists who have by and large avoided the elevation: the Rolling Stones, Bob Dylan, Leonard Cohen, Van Morrison, The Beatles. These artists were certainly given to expressing themselves musically, and to making statements through words, and that may have been enough, the elevating modulation imparting too strong a sense of following a pre-determined path. In relation to which, elevation's home in arrangement is important, arrangement with its functional air, and someone else's job, rather than song writing or composition per se, with their sense of personal commitment and conviction. It is also important that the elevation often belongs only to the instrumental domain, so that the sung voice - often the most immediate signal of expression - can be kept away from the technical device, and this is something to which I shall occasionally attend in my examples.

That said, an immediate task, if only for fun, is to take the side of the elevating modulation: that it is a device critically derided is easy to establish, both in the non-academic and academic domains, and this derision might even constitute part of its status as so-called 'popular music'. A lot of name-calling is directed at the elevating modulation, as a fate avoided by, for example, the regular shift from tonic to dominant in the major-key sonata form. Robert Anwood's website, gearchange.org, adopts a light-hearted tone throughout, no bad thing, but is nearly always critical of the modulation. Arranged alphabetically, adjectives used of examples include the following: blunt, 'cacophonic', dire, dreadful, dull, formulaic, grotesque, ill-advised, lazy, mediocre, predictable, rancid, savage, sickening, uncalledfor, and vicious (Anwood, 2003). The most critical entry is the one for 'I Will Always Love You' by Whitney Houston (1992), described by the site's external correspondents as, again alphabetically, bombastic, nauseating, toecurling, vomit-inducing, and unlistenable. Apart from adjectives and adjectival compounds, there are many extended metaphors and inventions, including the following three examples, with a fourth taken from the critical commentary on Houston's track: 
But it all goes downhill - or perhaps uphill - later on in the song, when the ideas have run out and it's time to shift gear. You can tell from his cautious "whoa-oh" that he's beginning to regret the decision, but by that point it's too late, and the whole song is forcibly grasped by the horns and dragged a tone higher. (Commodores, 'Easy')

Although it cries out for an obvious truck driver's gear change, it's so incompetently executed that you almost don't notice it's there. The keyboards seem to decide to change of their own chord [sic], while the bass is too busy doing other things; and the vocals lamely take up the new key, seemingly for want of anything better to do. There are no mitigating circumstances whatsoever. (Real Thing, 'You to Me are Everything')

Jimmy Ruffin's heartfelt "talkie bit" is rudely interrupted by this gear change. There's not a lot you can say about it, other than to concur with his sad cry of 'ohhhh' when it happens. That's the sound of a man retrospectively reading the small print of a contract he has already signed, realizing that he is now legally obliged to change key. (Jimmy Ruffin, 'Farewell is a Lonely Sound')

The blood vessel in my temple starts pulsing every time I hear her voice. I start muttering about the 'bloody key change', then go into full rant mode when the inevitable occurs. (Whitney Houston, 'I Will Always Love You')

Few of the 117 tracks are actively praised for their use of an elevating modulation, among which Michael Jackson's 'Man in the Mirror' ('pure genius') with REM's 'Stand' given 'benefit of the doubt' as being 'in the spirit of irony' (Anwood, 2003).4

In the academic literature, the elevating modulation fares no better. Everett and Griffiths go ahead and find bad examples. 'Worst offender?' asks Everett (Everett 1997, p. 151), selecting a track by Frankie Valli for the prize. 'It can be a bad idea', Griffiths warbles from his perch (Griffiths 2007, p. 40), poking fun at an example from Stevie Wonder in a footnote (p. 191). Ricci is more guarded, but a couple of points show a telling if wholly unsubstantiated association between the technical device and the venality of money-making: a Chicago track fades on its new key 'hopefully long enough in the minds of consumers for the songwriters, producers, and band members to make a handsome profit', while the footnote adds that the modulation could be 'cheap' as a 'way to extend a song whose paucity of ideas could not sustain it for an acceptable length' (Ricci 2000, p. 131). Commencing his study, Buchler admits that 'direct modulation might well seem to be a bit of a facile subject of inquiry' (p. 35) where the prevarication of 'might well seem to be a bit of' for 'is' indicates at least a degree of unease (Buchler 2008, p. 35). 
That said, despite their disparagement and dubiety, these sources all contain suggestive research. Anwood's site provides some general editorial matter, a commissioned and useful article by Dominic Pedler, entitled 'The truck driver's gear change: a muso's introduction' and, at the site's heart, its 117 audio examples, helpfully accessible by artist, song title and date. Everett's approach includes an important quantitative aspect, seen in the diagrams found at p. 284 of Everett 2009.5 Hughes (2003, pp. 60-110) and Doll (2011) both attend most usefully to the point of modulation, Hughes with reference to a track by Stevie Wonder, Doll in terms of the connection between verse and chorus. Buchler (2008) is closely tied to the theatrical origins of some of Frank Loesser's songs containing elevating modulations, concluding with a sophisticated passage from Guys and Dolls; Buchler also introduces a notational distinction (between a plus and an upward-pointing arrow) in voice-leading graphs. Capuzzo (2009) includes a most useful example (Example 2) and discussion listing six 'gauges of tonality', with monotonality at one end, his 'sectional tonality' at the other (Capuzzo 2009, pp. 158-9). However, Ricci 2000 is the most directly influential paper upon what follows, from which I diverge in emphasis in three respects: first, nomenclature, to which I shall soon return; secondly, Ricci examines the device in relatively sophisticated examples (by the band Chicago) where I attend by and large to simpler examples; finally Ricci, like Buchler, is concerned with the relationship between harmony and voice-leading, expressed graphically whereas, although those aspects are there in the background, my emphasis is primarily on harmony. Ricci concludes his study by suggesting four avenues for further work, and this paper is concerned only with the second of those ('a study of the pump-up in popular music in general, with an eye to discovering other examples of a structural use of the pump-up', p. 146), although of course it suggests further directions of its own.6

\section{Nomenclature}

Following a lively discussion of metaphors used to describe tonal elements, Brian Hyer concludes that 'there is in fact a strong correlation between tonal theories and conservative ideologies' (Hyer, 2002, p. 732). In the case of the elevating modulation, the terminology that has gathered around it is not so much conservative, at least immediately, as familiar and negative. Familiar: attitudes towards the device remind me of how people sometimes see their family, comfortingly consistent, but predictably dull, and reminiscent of Sontag's 'ultimate camp statement: it's good because it's awful' (Sontag 1982, p. 119). There appear to be three types of attribution: technical summary; metaphor, where the modulation is compared to something in the life world; and association, where the modulation is linked to an artist or genre noted for their use of the device. 
Technical summaries attempt to find a label for the modulation by selecting aspects of its direction, intervallic distance and temporal point. Examples include in French, 'la modulation au demi-ton supérieur en fin de chanson', in Italian 'modulazione un tono sopra' (and see Fabbri 2008), and ‘半音転調' ('han on ten cyou': half-note modulation).

In Welsh, ‘trawsgyweiriad' would be used, the same word as for 'transposition': literally 'traws-cyweiriad' or crossharmonization.7 The songwriter Jimmy Webb describes a 'final modulation', as opposed to the 'transitory modulation' (Webb 1998, p.241), close to the formal distinction referred to in harmony textbooks as modulation and tonicization.

Examples of metaphors include three published sources: the crowbar modulation, fleetingly mentioned by Peter Kaminsky (Kaminsky 1992, pp. 3 and 11), Adam Ricci’s pump-up modulation (Ricci 2000, pp. 130-1), and the truck-driver modulation, used with consistency and regularity by Walter Everett (see for example Everett 1997, footnote 18, p. 151 and Everett 2009 pp. 283-4). There is a small problem with the truck driver analogy: for Everett (Everett 1997, footnote 18 at p. 151) and for Griffiths (2007, pp. 40-1) the truck is used in order to suggest the clutch of a linking dominant.8 From private communications with Allan F. Moore and George Mowat-Brown, an alternative view is that the truck qua truck precisely avoids the linking clutch, and is thus, for example, Robert Gauldin's 'sectional modulation' (Gauldin 1997, p. 259-60): according to this view, this is why it's a truck rather than a car, for example. For Anwood, gear change 'reflects the utterly predictable and laboured nature of the transition, evoking a tired and over-worked trucker ramming the gearstick into the new position with his - or, to be fair, her - fist' (Anwood, 2003). The term could also leave open the suggestion of a person of limited skill, and such may be how a metaphor carries Hyer's conservative tendency. Everett is on the side of the composer-as-driver, and Peter Kaminsky's 'crowbar modulation' is also at the writer's shoulder, the latter term presumably indicating the way that the bar is used a lever to prise open objects or nails ( $O E D$ : 'by quarrymen, lumbermen, house-breakers etc'). Ricci's 'pump up' is intended (footnote 5, p. 130) to connote 'the crude yet buoyant musical effect of such an upward modulation'. Pump-up originates from water or the tyre to a car or bicycle. However, and unfortunately from the point-of-view of a useful term, 'pump up' runs into a more recent musical usage that employs 'pump up' to mean, as the $O E D$ sums up: 'to sound loudly, especially with a fast propulsive bass rhythm'. This then becomes tied specifically to volume, so that 'pump up the volume' means 'to increase or turn up the volume'. Perhaps there are too many pump-ups for comfort and, what's more, the use of an identical term might lead to an assumed connection between pumped-up musical parameters.

Examples of associations include "'Barry Manilow" tonality', fleetingly mentioned by McCreeless (1996, p. 106) and the arranger's modulation. Wayne Chase makes the relevant distinction between song and arrangement: 'It's 
not uncommon for a songwriter to write a song in a single key, only to have an arranger introduce a shift modulation (without authorization) for some artist covering the song. In such a case, the shift modulation is called an "arranger's modulation."' (Chase 2006, and see also Ricci 2000, p. 131). Alf Bjornberg describes a Swedish example in a private communication (and see Bjornberg 1987):

The extent to which Swedish Eurovision Song Contest music has stood out in terms of musical style has varied over the years, but one significant trait about which there exists a considerable degree of consensus is: a proper ESC song has to contain at least one semitone-up modulation. A not unusual term for this is the "schlager modulation" - the term is significant: until the mid-1950s, the German word "schlager" was used in Sweden for "mainstream popular song" in general, but in latter decades it is increasingly associated with the ESC (and in its general meaning replaced by the English "hit"). A common designation for this contest, and for the music performed therein, is Eurovisionsschlagern ("the Eurovision schlager").

For my undergraduate students around 2010, the modulation carried strong association with the Irish 'boy-band' Westlife.

This paper has already used new terms, the elevating form and elevating modulation, and I shall now explain this proposed improvement. Bringing together form and modulation nods to Robert Gauldin whose textbook includes binary both under 'modulation and tonicization 1' (Gauldin 1997, pp. 264-5) and under 'simple forms' (Gauldin 1997, p. 271). I considered escalation too anxious, and landed upon elevation: recall that the elevator or lift goes down as well as up. I think the metaphor is relatively neutral, and value the way that 'elevating modulation' opens up the possibility of the elegant noun 'elevation'.

As we approach concrete examples, one technical detail needs explanation. In terms of transposition level, measuring the distance between original tonic and modulation, my examples are all $\mathrm{T} 1$ and $\mathrm{T} 2 \mathrm{~T}$ : 1 is up by a semitone, T2 up by a tone. 9 In three examples (one from Mozart, two from Bing Crosby), I use T10 rather than T-2.10 The mathematical language takes less space, but also helps to minimize enharmonic decisions (is the new key $\mathrm{Db}$ or $\mathrm{C \#}$ ?), even though, by including specific keys for reference, I do have occasionally to make such decisions. Nearly all the examples are concerned with major key rather than minor. Footnotes will suggest further detail pertinent to a given example, but I do not include lists of other examples, leaving it to readers to discover their own, testing my models in so doing.

\section{Elevating Form}


In 1944 Bing Crosby made two records featuring the Andrews Sisters and an orchestra under the direction of Vic Schoen.11 'Ac-cent-tchu-ate the Positive', recorded in December, starts in F, modulates T10 to E flat (at 1'18, the modulation from 1'14 to 1'18), and stays there for the remainder of the record (which ends at 2'40': 49\%).12 '(There'11 be a) Hot Time in the Town of Berlin', on the other hand, also drops T10 (at 0'57:33\%), this time for the entry of the Andrews Sisters, from F to Eb; after a brief instrumental interlude in $\mathrm{Bb}\left(1^{\prime} 48-2^{\prime} 00\right), \mathrm{Eb}$, the lower of the first two keys is regained (at 2’01), so that a final elevation (T2) enables the original key to conclude (2’27 to 2'51: 86\%). Beginning in one key and ending in another, 'Ac-cent-tchu-ate the Positive' demonstrates elevating form; whereas '(There'll be a) Hot Time in the Town of Berlin' belongs to a smaller subset of tracks that clearly contain elevating modulations but do not demonstrate elevating form overall. A general principle from this comparison: an elevating form always contains an elevating modulation, but an elevating modulation can appear in a context where the overall track does not illustrate elevating form.

That exceptional subset apart, 13 since elevating forms are either present or not, they can be observed as quantitative proportions in a given repertory, such as a chronological collection of songs, an artist's career, or an album as a gathering of songs by a specific artist. To take an example, one can imagine a record collection in the late 1970s containing two collections of greatest hits: Barry Manilow's Greatest Hits, issued as a double album in 1978, and Paul Simon's Greatest Hits Etc issued in 1977. The Manilow album had eleven elevating forms in nineteen tracks, the Simon album one elevating form in fourteen tracks.

The point at which the modulation occurs can be observed with reference to exact time on a record, and my proposal is that this is then converted into a percentage point for the record as a whole. For example, with Manilow's Greatest Hits, the percentage figures average as $70.4 \%$; however, if we exclude 'Daybreak', unusually low at $40 \%$, the average is $74.25 \%$, between a low of $68 \%$ and a high of $80 \%$ (see APPENDIX: BARRY MANILOW ELEVATIONS). The percentage figures need to be regarded with a little scepticism, due to at least three things: differing editions of the same track, the distinction between a fade and a dead end, and an occasional issue over deciding the exact point at which a new key has arrived; 14 but very often the accuracy is appropriate and even suggestive. For example, two tracks both written by Tom Dicks and Myles Rudge, 'Right Said Fred' recorded by Bernard Cribbins and 'A Windmill in Old Amsterdam' recorded by Ronnie Hilton, both have T1 elevations, from C to $\mathrm{CH}$ at $46 \%$ and from $\mathrm{F}$ to $\mathrm{F} \#$ at $44 \%$ respectively, and in which both elevations have a relatively unobtrusive presence as marker of repeat, da capo. It may be possible to distinguish between $50 \%$ type EM and $75 \% \mathrm{EM}$, the latter likely to be a repeated chorus. There are rogue examples, where the elevation appears very early, as in the $4 \%$ of Elvis Costello's 'American Without Tears' (T2 from F to G at 10 seconds, of a track that fades at 4'29 track, and with a 
further T2 elevation at 2'28, 55\%) or very late, as in the $97 \%$ of 'We're Rockin in Rhythm' by Lorraine Feather (from $\mathrm{Db}$ to Eb, a T2 juxtaposition at 2' 42 of a track that ends dead at 2'47). Of course, form must always be tied to content, so that the early rogue example, the Costello, may not constitute elevating form as such, in that not enough material has been presented for elevating form to be registered.

Both Cribbins and Hilton examples belong to the instrumental domain, so that the voice is unaffected by the point of modulation. A pianist asked to accompany a children's performance of 'Old MacDonald Had a Farm' might decide to insert an elevation or two between verses for fun, or to alleviate boredom.15 Thus, the strophic song is one formal archetype liable to contain an elevation in performance or recording, as in an arrangement by Karl Jenkins of the Welsh song 'Myfanwy', or the recording of 'Abide With Me' by Jo Stafford and Gordon MacRae. Rosemary Clooney's rendition of 'God Bless America' shifts $\mathrm{T} 1$ from Ab to A, with an appeal to the audience to join in: 'Sing with me, this chorus okay, you know the words' (at 2'03 of 3'18: 62\%). Cat Stevens's version of 'Morning Has Broken' begins with an introduction in D, but arrives for its first verse T10, in C (0'14); another verse follows in C (0'55), after which, for a third verse, the music returns T2 to D (1'41); but for a final verse, the music returns to C (2'24), before ending again in D after a piano postlude (3'16). Thus, as form the track is another case of elevating modulation in a piece that does not exhibit elevating form overall, and whose elevations belong to pianist Rick Wakeman rather than singer Cat Stevens. 16

The term 'multiple modulation' could be used to describe a track with several similar modulations, and an important type of elevating form. Bobby Darin's 'Mack the Knife' (1959) starts in Bb and ends, T5 in Eb, by a series of $\mathrm{T} 1$ shifts. In terms of the song's form, the first key $(\mathrm{Bb})$ houses two verses, the others all one each.17

$\begin{array}{lllllll}\mathrm{Bb} & \mathrm{B} & \mathrm{C} & \mathrm{Db} & \mathrm{D} & \mathrm{Eb} & \text { end } \\ \text { 0'00 } & \text { 0'51 } & \text { 1'14 } & \text { 1'37 } & \text { 2'00 } & \text { 2'24 } & \text { 3'03 } \\ & & & & & & \\ & 28 \% & 40 \% & 53 \% & 66 \% & 79 \% & \end{array}$

By contrast, Beyoncé's 'Love On Top' (2011) begins its elevations late in the song (69\% through) but is thereafter consistent:

$\begin{array}{llllll}\mathrm{C} & \mathrm{Db} & \mathrm{D} & \mathrm{Eb} & \mathrm{E} & \text { end (fade) } \\ \text { 0’00 } & \text { 3’04 } & \text { 3’25 }^{\prime} & \text { 3'45 } & \text { 4’06 } & \text { 4'25 } \\ & & & & & \\ & 69 \% & 77 \% & 85 \% & 93 \% & \end{array}$


My brief discussion of elevating form is at most only a starting-point for further analysis. For example, a summary table (found at the end of the article) presents most of the tracks referred to in this paper, arranged by ascending percentage indicating the point at which the modulation occurs (multiple modulation have been excluded for the most part), and there is room for much more quantitative work of various kinds. The appendix, on Barry Manilow, provides a template for work on specific repertories. Further work can be done in identifying archetypes such as the strophic song, as well as closer work in mapping form to content.

\section{Elevating modulation: four models}

My four-part schema is derived from comparison with the way in which modulation is presented in standard harmony textbooks. For example, Gauldin (259-62) presents three types of modulation: sectional, pivot, and chromatic. The pivot matters little for the elevating modulation, which can be limited to Gauldin's sectional and chromatic. The sectional modulation simply asserts a new key without link, and George Pratt usefully has 'assertion' (Pratt p. 142); Gauldin's chromatic modulation is concerned specifically with modulation from I to V, and the role of 4\# and 4 natural. I adapt Gauldin's 'sectional' category directly, referring to it as 'juxtaposition', but I freely adapt Gauldin's 'chromatic', referring to it as 'transformation'. In truth, all four of my categories are to an extent both juxtaposed and transformed, but I preserve 'transformation' for the final category, only since it has the sense of a tonic's melding into the dominant of the new key. As we shall see, the categories can also be presented with reference to the standard cadences. Diagram One gives a schematic overview of the four models for T1 and T2.

DIAGRAM ONE: see appendix

\section{Tonic-to-tonic juxtaposition}

Mapping directly onto Gauldin's sectional modulation, this model simply cadences on the tonic before picking up in a new key. Aretha Franklin's 'Think' sounds like an abrupt cut from Bb to B (at 1'01 of a 2'18 record: 44\%). The passage in question (from 0'44-1'02), concerning the word 'Freedom', ends with the upward shift, so that a little connecting melody in bass and piano first heard at 0'52-3, landing on B flat, at 1'01-2 lands on B natural (see ex. 1). The modulation is limited to the instrumental domain.

EXAMPLE ONE: see appendix

By comparison, the second modulation of Nat King Cole's 'Let There Be Love' (at 1'52 of 2'44 total: 68\%) takes action to smooth out the cut. The first key (C) is asserted by a series of four blues-plagal cadences (see ex. 2.1), whereupon George Shearing's piano lands on the note F, common to both $\mathrm{C}$ and $\mathrm{Db}$, instigating a rising line $\mathrm{F}, \mathrm{Gb}$, 
$\mathrm{Ab}, \mathrm{Db}$ (see ex. 2.2), which is then imitated at a slower pace in viola (see ex. 2.3), under a repeated $\mathrm{Db}$ in piano laced with $\mathrm{Ab}-\mathrm{Db}$ fanfares. The blues-plagal cadences have the note $\mathrm{C}$, the other note common to both keys, prominent at the top of the strings, so that there is perhaps a sense of push towards the $\mathrm{Db}$. Shearing's phrase is in turn derived from the opening vocal phrase (see ex. 2.4). 18

(EXAMPLE TWO: 1, 2, 3, 4): see appendix

As with Shearing, the $\mathrm{T} 1$ elevation as juxtaposition is often a small effort of sewing over the connection. It should not be forgotten that the sheer contrast in notes - two notes consistent, five notes new - is considerable. The Mindbenders' version of 'A Groovy Kind of Love' happens to leave its tonic A major resounding, as the lead guitar begins its stepwise ascent, and thus draws attention to this aspect of the T1 juxtaposition (at 1'15 of 1'58, 64\%). 19

For T2, I turn to an example from a children's TV programme Bob the Builder, composed by Paul K. Joyce. The first key (E) is asserted strongly by a perfect authentic cadence, so that in order to reach the first note of the following chorus in the new key of F\# (at 0'38 of 0'52: 73\%), the singer has to leap a major ninth, and that lusty vocal commitment to the new key is perhaps a feature of this model. In 'Beautiful Sunday' (at 2'18 of 3'12: 76\%), in fact, Daniel Boone's voice has to leap an octave plus tritone to connect a low $\mathrm{C}$ to the high $\mathrm{F}$ sharp instigating the chorus in D. This track has also introduced its D major in the second period of the chorus (at 1'03-7), where the chord substitutes for the IV (of C) chord heard previously (at 0’47-51).

'Lay Down' by the Strawbs presents a more extended example of a tonic-tonic juxtaposition, T2, but including an important reference to a mediating relative minor. In fact, the progression could easily be a pivot modulation preparing a modulation to V! (See ex. 3) The passage occurs twice in the track, so that the track ends on G\# major, T4 in relation to the opening E (first modulation at 2' 50 of total 4'33: 62\%, second modulation at 4'25: 97\%). The first modulation follows upon a chorus that ends on the tonic E. Guitar left alone, a progression then follows that connects the relative minor $\mathrm{CH}$ to $\mathrm{F} \#$ by a stepwise bass descent; $\mathrm{F}$ sharp has its $1^{\wedge}$ as upper part. $\mathrm{F} \#$ is then prolonged by brief reference to its subtonic, also E, the first tonic, before proving to be the tonic of the next verse.

EXAMPLE THREE: see appendix

\section{Dominant-to-tonic juxtaposition}

While the tonic-to-tonic juxtaposition essentially presents two quite separate tonal areas, the first firmly concluded before the second starts, the dominant-to-tonic juxtaposition can be seen as a particular form of deceptive cadence. 
Many examples can be found where, although the juxtaposition is between the dominant of the first key and the tonic of the second, repeated phrase structure means that the juxtaposition continues to have a strong secondary sense of juxtaposing tonic to tonic. 'Sleigh Ride' by the Ronettes presents a simple example (at 0'50 of 2'56 total: $28 \%$ ), the first of several modulations in a track with a bizarre ending. The basic repeated pattern is I-vi-ii-V, in C, the whole lifted to $\mathrm{Db}$. Sung to the phrase 'ding-a-ling-a-ling-a-ding-dong-ding', the melodic figure progresses from $\mathrm{G}$ through $\mathrm{A}$ to $\mathrm{B}$, so that the last note is left dangling in its progress to $\mathrm{C}$, while the pattern descends to $\mathrm{Ab}$ (over $\mathrm{Db}$ ) to progress through $\mathrm{Bb}$ to $\mathrm{C}$. It's that 'dangling' of the notes pertaining to $\mathrm{V}$, or $\mathrm{V} 7$, that matters in the juxtaposition, and why this category deserves its separation from the tonic-tonic juxtaposition. That said, phrase repetition ensures that the juxtaposition of, in this case, G7 and Db is kept within the firm control of the overarching shift from $\mathrm{C}$ to $\mathrm{Db}$ (See EX. 4).

EXAMPLE FOUR: see appendix

This model then becomes as much about the nature of cadential dominants, and their prolongation, as the modulation itself. Barry Manilow's 'Weekend in New England' (at 2'55 of 3'46 total: 77\%) has its dominant both tonicized and prolonged, so that the eventual modulation, T1, demonstrates the elevating modulation's clichéd traits of arrival, release, drama, bombast: a locus classicus, indeed.20 The modulation follows a bridge section which includes a composed-out plagal cadence, a stepwise descent from $\mathrm{F}$ to $\mathrm{C}$, in which the note $\mathrm{C}$ is prominent melodically. This melodic note then rises to D, through V7/V (D7) to G: this D, to the word 'bad', belongs only to C and not to the resulting $\mathrm{Db}$, though perhaps its effect is mitigated somewhat by the harmony's adopting the version of $\mathrm{V}$ that utilizes chord IV (or ii7) over a V bass. Indeed, at the very point of crossover, voice lands on $\mathrm{C}$ with $\mathrm{D}$ as upper neighbour, for 'tell me', while the Db section starts with the note F, the notes $\mathrm{C}$ and F, as we have already seen, belonging to both camps. Be that as it may, there is no doubt that the modulation depends upon the juxtaposition of $\mathrm{G}$ and $\mathrm{Db}$, ensuring surprise at the point of crossover.

For a sophisticated presentation of the dominant-tonic juxtaposition, T1, we turn to the comic song, 'The Song of Patriotic Prejudice' by Michael Flanders and Donald Swann, whose elevation (at 1'28-31 of 2'41 total: 55\%) is used to illustrate the Welsh at the line 'he sings far too loud, far too often, and flat'. While the word 'flat' suggests a downward shift, the key is in fact rises $\mathrm{T} 1$ from $\mathrm{Bb}$ major to B major. The melodic line over F7 is, as heard previously in the track (at 0.40-2), A leading to $\mathrm{C}$ through $\mathrm{Bb}$ as passing note and $\mathrm{B}$ natural as chromatic passing note (CPN in the example). But now the B natural is excruciatingly held (for 'and flat'), under which the piano plays the familiar melody 'Oh du lieber Augustin', starting with F sharp and in B, and the music continues in B major (See Ex. 5).21 
EXAMPLE FIVE: see appendix

Surprise is built into the tonal structure of the dominant-tonic cadence, T1, but phrase structure can also play its part, giving rise to abrupt cuts.22 A useful touchstone is found in The Beach Boys, 'Dance Dance Dance' - T1, from $\mathrm{G}$ to $\mathrm{Ab}$ - where, after an instrumental solo, the verse has just restarted with its familiar phrase (I-IV-V) ending on $\mathrm{D}$ as dominant, only for the next chord and line to wrench upwards to $\mathrm{Ab}$. The voice is involved in the juxtaposition, so that the melodic line itself includes the key change, resulting in a leap from $\mathrm{D}$ of the $\mathrm{D}$ chord to a blues-inflected $\mathrm{G}$ flat over the $\mathrm{Ab}$ (See Ex. 6).23 The moment of crossover is 1'14, of a record that fades at 1'58: 62\%.24

EXAMPLE SIX: see appendix

For the dominant-tonic juxtaposition, T2, we can again refer to Barry Manilow, not least since juxtaposing the relevant moments from the two Manilow examples ('Weekend in New England' and 'Mandy') is an interesting exercise, suggesting similarities in effect between the T1 and T2 transpositional level. In 'Mandy', the modulation simply connects two choruses that concern themselves with notes $1^{\wedge}$ over I leading to $2^{\wedge}$ over $\mathrm{V}$. Thus the $\mathrm{Bb}$ chorus ends on the note $\mathrm{C}$ over $\mathrm{V}$, which $\mathrm{C}$ then becomes the $1^{\wedge}$ of the following $\mathrm{C}$ major section. The bass relation at point of crossover is a perfect fourth, a plagal relationship between F and C, denied the status of plagal cadence by the presence of F7 rather than F plain. (The modulation is at 2'43 of a record lasting 3'23: 80\%.)

A dominant seventh (F7, albeit ii over V) is also juxtaposed with a tonic (C), T2, in 'Goodbye to Love' by the Carpenters, but what's particularly interesting at this moment (2'00 of total 3'54: $51 \%$ ) is the entry of Richard Carpenter's overdubbed choir for the line 'There may come a time when I will see that I've been wrong', bringing in a richer harmonic palette at the point of modulation. The elevation ensures that the first guitar solo is in B flat (1'23-51), while the second is in $\mathrm{C}\left(2^{\prime} 48\right.$ to the fade at 3'53).

Unlike 'Mandy' and 'Goodbye to Love', with their dominant seventh chords, 'I Will Always Love You', by Whitney Houston, really does contain a plagal cadence to connect E, as V of the first key A, to the following second key B. There is drama aplenty at 3'01-08, in the ritardando, lunga pausa, and the solitary drum beat, 25 but a continuo player might nevertheless have filled the space between $\mathrm{E}$ and $\mathrm{B}$ with connecting passing notes (E, D\#, C\#, B) harmonized in tenths. The modulation occurs at 3’09 in a record that ends dead at 4’23, $71 \%$.

A compressed form of 'double-plagal' connection can be found in 'Up the Junction' by Squeeze, in order to engineer the T2 elevation from D to E (at 1'50 of 3'05 total: 59\%), by simply presenting the three chords, D, A, E. This is a particular property of the T2 elevation.26 If the Squeeze example is compressed, 'Back on the Chain Gang' 
by the Pretenders illustrates the same principle given more space. The track starts In D, but shifts to D minor for its bridge section. The bridge then ends on $\mathrm{A}$ as $\mathrm{V}$, then to $\mathrm{E}$ as plagal, a dominant-tonic juxtaposition, T2 (at 2'38 of 3'49: 69\%). Illustrating the passage from 2'24-45, beginning with the words, 'But I'll die as I stand here today', the example shows how an extra bar is built in to the crossover (See Ex. 7.1); however, a most effective part of the stitching between the keys is that the bass plays an arpeggiated figure first on the A chord at the asterisk, and continuing onto the E chord and the new key (See Ex. 7.2). The voice is much involved as, over the modulation, Chrissie Hynde sings the phrase 'making us part', to the notes C\#-D-E upwards over the A chord, then E-D\#-C\# downwards, in E, the very word 'part' crossing the key change in a most affecting way.27

EXAMPLE SEVEN $(1,2)$ : see appendix

\section{Dominant Handover: the dominant-dominant juxtaposition}

'The dominant handover' is my short-hand description of the dominant-dominant juxtaposition, as though a baton is being passed in a relay, and is a strange hybrid of both deceptive and authentic cadences. Walter Piston identifies the technique - as a chromatic 'shift rather than modulation' (p. 226) - used in the Scherzino of Schumann's Faschingsschwank aus Wien (p. 227) and which Piston describes as a 'well-considered joke', although the musical example hides the fact that the short passage, in A major, is in fact a return to the home key of B flat major, having reached A via D flat. 'There is no modulating process, there is only a modulated state', Piston comments.

For T1, a basic version can be found in 'Summer Holiday' by Cliff Richard (69\%), where the second bridge section ends by tonicizing $\mathrm{V}$ of $\mathrm{E}$ which is then immediately raised to $\mathrm{V}$ of $\mathrm{F}$. At 0 '39-41' the corresponding dominant leads simply back to E as tonic. The second bridge section also passes through iii ('we've seen it in the movies') in order to reach V ('let's see if it's true', at 1'33 of 2'14: 69\%), and keeps $5^{\wedge}$ of $\mathrm{E}$ in focus, above G\# minor as iii, and as the destination of the tonicization of V. Voice is included in the shift, so that 'true' now occupies two notes (B and C) where at first appearance (at 0’39-41) it took only one (B). The semitone rise from B to C thus sews and perhaps softens the melodic consequence, as the melody in F brings in all five notes absent from E, and in fact studiously avoiding the note E itself, the melody lacking a strong leading-note. Note that the second dominant is in a weaker metrical position in the bar than the first, a characteristic of this model.

Much as with the dominant-tonic juxtaposition, the compositional possibility now resides primarily in prolonging the dominant, and this is found to great dramatic effect in the song 'Cabaret' from the filmed musical (at 2'56 of 3'31 total: 83\%), perhaps best heard in a live 1974 recording by Liza Minnelli at the Winter Garden on 
Broadway in New York (at 3'21 of 3'46 total: 89\%). This is our T2 example of the dominant handover, since the passage effects an elevation from $\mathrm{Bb}$ to $\mathrm{C}$, but with considerable attention given to $\mathrm{F} 7$ as $\mathrm{V} / \mathrm{Bb}$ and $\mathrm{G} 7$ as $\mathrm{V} / \mathrm{C}$. The passage might be taken back to the major-minor mixture (at 'And as for me'), Bb minor as iv to F as I, before ii (G minor) leading to V7/V ('my mind up back in Chelsea') sets up V7 ('when I go'). The note C ('go') is prolonged for all of six seconds in the live recording but, rather than descend to $\mathrm{Bb}$, it leads instead to $\mathrm{B}$ natural for a melodic arpeggiation of G7 descending with determination ('going like Elsie') and a fall to the low G to begin the chorus in C. The $\mathrm{Bb}$ found for example at chord ii of our bridge section reappears as part of V7/IV (at 'it isn't that long a stay').

'Rainy Days and Mondays' by the Carpenters expands the dominant handover to include reference to chord ii as a pre-dominant: $\mathrm{Fm} 7-\mathrm{Bb} 7$, handing to $\mathrm{Gm} 7$ to $\mathrm{C} 7$ (at 2'40 of total 3'33: 75\%). The exact connection is thus between $\mathrm{Bb} 7$ and $\mathrm{Gm} 7$, rather than $\mathrm{Bb} 7$ and $\mathrm{C} 7$, and this is an important possibility for this model and the dominanttonic juxtaposition and tonic-dominant transformation: that the dominant can be preceded by pre-dominants.

A correspondence to our earlier discussion about T2 and the plagal relationship, the Squeeze example, can be found in 'The Ties that Bind' by Bruce Springsteen. The Springsteen starts in C, and the modulation picks up (at 2'33) from G dominant, into four chords: G, D, A, A, and then to D at 2'35 (of 3’30 total: 74\%). Later, Springsteen recalls C at 2.55 at an exciting moment: 'the ties that bind'.

The dominant handover in principle can reappear in different transpositional settings. For example, 'Paint a Vulgar Picture' by The Smiths oscillates between C and A, T9 one way, T3 the other, but always using the dominant handover at the point of crossover, A leading to F\# to get from $\mathrm{D}$ to $\mathrm{B}, \mathrm{F} \#$ leading $\mathrm{A}$ to return to $\mathrm{D}$. The track is a genuine oscillation, but does end in the second key, so qualifies as a strict elevating form!

'She's Gone' by Hall and Oates is one of the most breath-taking dominant handovers, covering three distinct chromatic steps to effect a shift from E to G. The passage arrives late in a long track that fades at 5'12. The elevations begin at 4'18, where B as dominant of $\mathrm{E}$ ascends first to $\mathrm{C}$ (at 4'18), to $\mathrm{C}$ sharp (at 4’24), to D (at 4'30), the final dominant preparing the final chorus in $\mathrm{G}$ at 4’36. In terms of arrival, 4’36 seems the right point to take as the formal new key, so $88 \%$ through. Another example of a chromatic progression of dominant handovers can be found in Cleo Laine's recording of 'I Hear Music' by Frank Loesser, with Laurie Holloway at the piano. Earlier in the recording (1'02-4), Holloway has composed-out V7 as a scale, in Ab major thus: Eb, F, G, Ab, Bb, C, Db, Eb. At the point of crossover, this scale is heard, followed by the same beginning on $\mathrm{E}$ (as $\mathrm{V}$ of $\mathrm{A}$ ), then on $\mathrm{F}$ (as $\mathrm{V}$ of $\mathrm{Bb}$ ), followed by $\mathrm{Bb}$ as new tonic (1'52-58). Thus the elevation is T2 but through three chromatic steps, all dominant-to-dominant. (The track lasts 2'58: 66\%). 
A final composing-out of a dominant handover can be found in 'Up Where We Belong', recorded by Joe Cocker and Jennifer Warnes. The modulation is up a semitone from D to E flat. The linking passage is from 2' 53 to $3^{\prime} 07$ of a track that lasts $3^{\prime} 54$, just short of $80 \%$ of the way through. At 2' 53 , the music shifts from tonic D to a briefly tonicised dominant A; A then becomes a common tone for a T8 drop to F, which commences the linking passage consisting of a chromatic descent in bass over which a set of tone descents: F-C-Eb-Bb-Db-Ab. The last chord then becomes IV, leading to V of E flat major, a semitone above the original tonic (See Ex. 8). Simple but effective, and clearly an analogy to the words: like love, the music lifts (us) up.

EXAMPLE EIGHT: see appendix

\section{Tonic-dominant transformation}

Finally, we reach the tonic-dominant transformation, a genuine case of a change in the tonic itself into the dominant of the new key, but at the same time closely related to the tonic-tonic juxtaposition. For $\mathrm{T} 1,1^{\wedge}$ of I often functions as a common-note to lead as tendency tone upward to $1^{\wedge}$ of IIb. For T2, the common notes are $3^{\wedge}$ and $5^{\wedge}$ of I which continue into V7/II. Frank Sinatra's 'The Lady is a Tramp' is a simple example where the track starts in B flat major and elevates to B major at 1'36 of a record lasting 3'14 (49\%). The linking dominant (F\#7) appears at 1'34, and leads directly to the new key. This example is much concerned at the point of crossover with $1^{\wedge}$ both as the note concluding the previous verse and instigating the next one - the trumpet sustains the note across the transformation so that the transformed $1^{\wedge}$ has a strong directional capacity.

A more composed-out melodic element is found at the crossover of 'Take Good Care of My Baby' by Bobby Vee, taking the music from $\mathrm{F}$ to Gb, a passage found at 1'37-40: 1'37 (F), 1'40 (Db7), 1'43 (Gb). The melody: F-E-DE (from 'take good care of my') over F, is altered into F-Eb-Db-Eb-F (Gb-Ab-Bb) over Db7, to lead to Gb. (The track fades at 2’28: $70 \%)$.

A minor-key example is provided by Bobby Hebb's 'Sunny' where, at the first point of crossover, E minor leads to $\mathrm{C}$ (the guitar at 1'00-01) to lead to F minor. This is another multiple modulation: F minor arrives at 1'02 (39\%), F\# minor at 1'32 (57\%, and G minor at 2'02 (76\%), for the record to fade at 2'40.

These three examples reside in the instrumental domain, while an example of a vocal transformation is found in 'Silence is Golden' by the Tremeloes, a wordless passage from 1'54 to 2'02, a T1 elevation, where the voice lands on $\mathrm{C}$ as $\mathrm{V}$ of $\mathrm{F}$ (at 2’00), a note both dreamy and fruity. (The record lasts 3'06: 66\%). (See Ex. 9) 
For the T2 tonic-dominant transformation, Dusty Springfield, 'You Don’t Have to Say You Love Me', where $\mathrm{D}$ as tonic, a major mixture for a chorus following a D minor verse, leads through B as V/E to E, T2 (at 2'20 of 2'46 total: $84 \%$ ). For the voice, $\mathrm{A}$ as $5^{\wedge}$ in $\mathrm{D}$ ('believe me') leads to $\mathrm{B}$ as $1^{\wedge}$ of $\mathrm{B}$ ('believe me') and $5^{\wedge}$ of $\mathrm{E}$.

\section{Combined models in multiple modulations}

Finally, I draw attention to tracks that combine different models. As we saw in our discussion of elevating form, the familiar model of a track using multiple modulation is that the same modulating device and $\mathrm{T}$ level recur, so that all five T1 modulations in Bobby Darin's Mack the Knife are tonic-dominant transformations, while all four T1 modulations in Beyoncé's 'Love on Top' appear to be dominant-tonic juxtapositions, but prepared by VIb immediately before the dominant. However, some tracks use both differing transpositonal level as well as, perhaps more rarely, differing models.

Elvis Costello's 'Lovable', contains three dominant handovers traversing a total of T5: the first and third T2 with a tonicized first dominant, the middle one $\mathrm{T} 1$ without tonicizing $\mathrm{V}$ (from A to B at 1'38 of 2'50 total, $58 \%$, from B to $\mathrm{C}$ at $2^{\prime} 00,71 \%$, from $\mathrm{C}$ to $\mathrm{D}$ at $\left.2^{\prime} 23,84 \%\right)$.

Petula Clark’s 'If I Only Had Time' has two T1 modulations: Bb to B then C. The second is a tonic-tonic juxtaposition, B at 2'02 (58\%), C at 2'13 (the record lasts 3’30: 63\%). The first is a more circuitous affair, getting from $\mathrm{Bb}$ to $\mathrm{B}$ via $\mathrm{G}$ (at 1'41). $\mathrm{G}$ is then in a repeated phrase landing on $\mathrm{C}$, before a cut to $\mathrm{F}$ sharp as $\mathrm{V} / \mathrm{B}$ at 1'56.

Barry Manilow’s 'I Write the Songs traverses T6 across two modulations, the first a dominant-tonic juxtaposition T4 (at 2'34 of 3'55 total: 66\%), the second a tonic-dominant transformation T2 (at 2'59: 76\%). The first of those is interesting in that the melodic $3^{\wedge}$ of $\mathrm{C}$ as $\mathrm{V} / \mathrm{F}$ forms a common note with the ensuing A major chord.

This is an appropriate point to mention a most sophisticated example, 'You're the Inspiration' by Chicago, the subject of a compelling discussion by Adam Ricci, and which, from this perspective, contains a modulatory passage T4 from B to D\# (at 0'39 to an eventual 0'51 of 3'48 total: 22\%) and three dominant-tonic juxtapositions, two T3 from $\mathrm{Ab}$ to $\mathrm{B}$ (at 0'12: 5\%) and from $\mathrm{Eb}$ to $\mathrm{Gb}$ (at 1'04: 28\%) and one $\mathrm{T} 11$ from $\mathrm{Gb}$ to $\mathrm{F}$ (at 2'59: 79\%). The final and elevated key, F (at 2'59), could be one of five possibilities: $\mathrm{T} 3$ of $\mathrm{Db}(\mathrm{V} / \mathrm{Gb}), \mathrm{T} 11$ of $\mathrm{Gb}, \mathrm{T} 2$ of Eb, T6 of B, and T9 of $\mathrm{Ab}$. 


\section{Conclusion}

This in turn brings us back to Carl Schachter. To return to the opening discussion of Mozart and Schachter, the problem passage of 'Voi che sapete' is, from this perspective, a dominant-tonic juxtaposition, T3 from F to Ab. At the point of crossover, the key of $\mathrm{Ab}$ is $\mathrm{T} 8$ in relation to the $\mathrm{C}$ chord, $\mathrm{V}$ of $\mathrm{F}$. In turn, the key is $\mathrm{T} 10$ in relation to the home key of $\mathrm{Bb}$. This is a timely reminder, then, that all these examples need to return to their context for closer or specific analysis. However, there does seem to be evidence for enough common ground in the examples above for the 'abstract schema' to claim some validity.

My chief conclusion is that when we speak of the elevating modulation, or indeed any other term, in the singular, we mean a plurality, but by no means as many categories as there are examples. I suggest that elevating modulation is best seen both as a localized device and formal category, and that as such it deserves a place in the harmony textbook. That said, I wholeheartedly concur with the spirit of Ricci's third direction for future research (see footnote 6): the challenge to examine specific repertories, both so-called popular and so-called classical, both recording-based and score-based, with a view to discovering when these devices became established. I trust that, while the modulation always depends on context, the variety of models provides interest: in other words, one way of appreciating the elevating modulation is to attend to the modulation. I hope finally that my scheme gives listeners the motivation to revisit examples quickly passed over.

TABLE: selected tracks referred to in the paper arranged by percentage point at which modulation occurs:

APPENDIX: Examples and Barry Manilow elevations 
TABLE: selected tracks referred to in the paper arranged by percentage point at which modulation occurs

4\% American Without Tears

$28 \% \quad$ Sleigh Ride, first modulation

33\% (There'll be a) Hot Time in the Town of Berlin, first modulation

44\% A Windmill in Old Amsterdam

$44 \% \quad$ Think

46\% Right Said Fred

49\% Up the Junction, first modulation

49\% Ac-cent-tchu-ate the Positive

$49 \% \quad$ The Lady is a Tramp

$51 \% \quad$ Goodbye to Love

$55 \% \quad$ A Song of Patriotic Prejudice

$59 \% \quad$ Up the Junction, second modulation (return)

$62 \% \quad$ God Bless America

$62 \% \quad$ Lay Down, first modulation

62\% Dance Dance Dance

64\% A Groovy Kind of Love

$65 \%$ I Am What I Am

$66 \% \quad$ I Hear Music

$66 \%$ Silence is Golden

$68 \%$ Let there be love (second modulation)

$69 \%$ Back on the Chain Gang 
$69 \% \quad$ Summer Holiday

70\% Take Good Care of My Baby

70\% Since You Been Gone (Rainbow)

$71 \% \quad$ I Will Always Love You

$73 \% \quad$ Bob the Builder

73\% The Ties that Bind

75\% Rainy Days and Mondays

$76 \% \quad$ Beautiful Sunday

77\% Weekend in New England

$80 \% \quad$ Mandy

$80 \% \quad$ Up where we Belong

83\% Cabaret, film version

84\% You Don't Have to Say You Love Me

$84 \% \quad$ I Get a Kick Out of You

$85 \% \quad$ Dreamer

86\% (There'll be a) Hot Time in the Town of Berlin, second modulation (return)

$88 \%$ She's Gone

$89 \% \quad$ Cabaret, live version

97\% We're Rockin in Rhythm

97\% Lay Down, second modulation 


\section{BIBLIOGRAPHY}

Anwood, Robert 2003.www.gearchange.org

Arnold, Matthew 'The Study of Poetry' (1880) in P. J. Keating (ed.) Matthew Arnold: Selected Prose

(Harmondsworth, Penguin, 1970), pp. 340-66.

Bailey, Robert 1977. 'The Structure of the Ring and its Evolution', $19^{\text {th }}$-Century Music, 1/i, pp. 48-61.

Björnberg, A. 1987. En liten sång som alla andra: Melodifestivalen 1959-1983 (Diss., Gothenburg: University of Gothenburg, Dept. of Musicology)

Buchler, Michael 2008. 'Modulation as a Dramatic Agent in Frank Loesser's Broadway Songs', Music Theory Spectrum 30/1, pp. 35-60.

Guy Capuzzo 2009. 'Sectional Tonality and Sectional Centricity in Rock Music', Music Theory Spectrum, 31/1, pp. $157-74$.

Chase, Wayne 2006. How Music Really Works: the Essential Handbook for Songwriters, Performers, and Music Students, accessible at: www.howmusicreallyworks.com

Christensen, Thomas 2001. 'Theoretical and Analytical Method', The Disciplines of Musicology, Musicology, in Stanley Sadie (ed.). The New Grove Dictionary of Music and Musicians (2 $2^{\text {nd }}$ ed.) (London: Macmillan).

Doll, Christopher 2011. 'Rockin' Out: Expressive Modulation in Verse-Chorus Form', Music Theory Online, 17/3

Everett, Walter 1997. ‘Swallowed by a Song: Paul Simon's Crisis of Chromaticism', in John Covach and Graeme M. Boone, Understanding Rock: Essays in Musical Analysis, pp. 113-53. (New York: Oxford University Press)

Everett, Walter 2009. The foundations of rock: from "Blue suede shoes" to "Suite: Judy blue eyes" (New York: Oxford University Press) and supporting website: http://global.oup.com/us/companion.websites/9780195310245

Fabbri, Franco 2008. Il suono in cui viviamo. Saggi sulla popular music (Il Saggiatore Tascabili)

Gauldin, Robert 1997. Harmonic Practice in Tonal Music (New York: Norton)

Griffiths, Dai 2007. Elvis Costello (London: Equinox) 
Hughes, Tim 2003. Groove and Flow: Six Analytical Essays on the Music of Stevie Wonder (Ph.D. dissertation, University of Washington)

Hyer, Brian 2001. 'Tonality' in Stanley Sadie (ed.). The New Grove Dictionary of Music and Musicians (2 ${ }^{\text {nd }}$ ed.) (London: Macmillan). Also in Thomas Christensen (ed.), The Cambridge History of Western Music Theory

(Cambridge: Cambridge University Press, 2002), pp. 726-52.

Kaminsky, Peter 1992. 'The Popular Album as Song Cycle: Paul Simon's Still Crazy After All These Years' College Music Symposium 32, pp. 38-54.

Krebs, Harald 1981. 'Alternatives to Monotonality in Early Nineteenth-century Music', Journal of Music Theory, 25/1, pp. 1-16.

Lambert, Philip 2007. Inside the mind of Brian Wilson: the songs, sounds and influences of the Beach Boys' Founding Genius (New York: Continuum)

Manilow, Barry 2000. The Barry Manilow Anthology (Milwaukee: Hal Leonard Corporation)

Maus, Fred E. 2003. 'Modulation' in Shepherd, John, David Horn, Dave Laing, Paul Oliver and Peter Wicke (eds.), 2003: Continuum Encyclopaedia of Popular Music of the World, volume 2: Performance and Production (London and New York: Continuum), pp. 555-6

McCreless, Patrick 1996. 'An Evolutionary Perspective on Nineteenth-Century Semitonal Relations' in William Kinderman and Harald Krebs (eds.) The Second Practice of Nineteenth-Century Tonality (Lincoln: University of Nebraska Press), pp. 87-113.

Metzer, David 2012. 'The Power Ballad', Popular Music ,31/3, pp. 437-59.

Pratt, George 1984. The Dynamics of Harmony: Principles and Practice (Buckingham: Open University Press).

Ricci, Adam 2000. 'A "Hard Habit to Break": the Integration of Harmonic Cycles and Voice-Leading Structure in Two Songs by Chicago', Indiana Theory Review, 21, pp. 129-146.

Schachter, Carl 1987. 'Analysis by Key: Another Look at Modulation', Music Analysis, 6/3, pp. 289-318, also in Unfoldings (New York: Oxford University Press, 1999), pp.

Schoenberg, Arnold 1969. Structural Functions of Harmony (London: Faber) 
Sontag, Susan 'Notes on "Camp”' (1964) The Susan Sontag Reader (Harmondsworth, Penguin, 1982), pp. 105-19.

Tovey, Donald Francis 1949. 'Tonality in Schubert', Essays and Lectures on Music (Oxford, 1949), pp. 134-59

Webb, Jimmy 1998. Tunesmith: Inside the Art of Songwriting. (New York: Hyperion).

Zollo, Paul 1997. Songwriters on Songwriting (expanded ed.) (New York: Da Capo). 


\section{DISCOGRAPHY}

Russ Ballard, ‘Since You Been Gone', Winning (Epic, 1976)

The Beach Boys, 'Dance, Dance, Dance', Today! (Capitol, 1965)

Beyoncé, ‘Love On Top’, 4 (Columbia, 2011)

Bob the Builder, 'Bob the Builder' theme tune (BBC, 1998)

Daniel Boone, ‘Beautiful Sunday’ (Penny Farthing, 1972)

The Carpenters, 'Rainy Days and Mondays', Carpenters (A \& M, 1971)

The Carpenters, 'Goodbye to Love', A Song for You (A \& M, 1972)

Chicago, 'You're the Inspiration', Chicago 17 (Full Moon, 1984)

Petula Clark, 'If I Only Had Time', Just Pet (Pye, 1969)

Ronnie Clifton, ‘A Windmill in Old Amsterdam’ (HMV, 1965)

Rosemary Clooney, 'God Bless America', The Last Concert (Concord, 2002)

Joe Cocker and Jennifer Warnes, 'Up Where We Belong' (An Officer and a Gentleman original soundtrack, Island, 1982)

Nat King Cole, 'Let There Be Love', Nat King Cole Sings/George Shearing Plays (Capitol, 1962)

Phil Collins, ‘A Groovy Kind of Love’ (Buster original soundtrack, Virgin, 1988)

Elvis Costello, 'Lovable', King of America (F-Beat, 1986)

Elvis Costello, ‘American Without Tears', King of America (F-Beat, 1986)

Bernard Cribbins, 'Right Said Fred' (Parlophone, 1962)

Bing Crosby and The Andrews Sisters, with Vic Shoen \& His Orchestra, 'Ac-cent-tchu-ate the Positive' (Decca, 1944)

Bing Crosby and The Andrews Sisters, with Vic Shoen \& His Orchestra, '(There'll be a) Hot Time in the Town of Berlin' (Decca, 1944) 
Bobby Darin, 'Mack the Knife' (Atco, 1959)

Celine Dion, 'The Power of Love', The Colour of My Love (Epic, 1993)

Lorraine Feather, 'We're Rockin' in Rhythm', Café Society (Sanctuary, 2003)

Flanders and Swann, 'A Song of Patriotic Prejudice', At the Drop of Another Hat (Parlophone, 1964)

Aretha Franklin, 'Think', Aretha Now (Atlantic, 1968)

Gloria Gaynor, 'I Am What I Am', I Am Gloria Gaynor (Chrysalis, 1984)

Hall and Oates, 'She's Gone', Abandoned Luncheonette (Atlantic, 1973)

Bobby Hebb, ‘Sunny’ (Philips, 1966)

Whitney Houston, 'I Will Always Love You' (The Bodyguard original soundtrack, Arista, 1992)

Karl Jenkins, Cory Band, and Cantorion, 'Myfanwy', This Land of Ours (EMI, 2007)

Cleo Laine and Laurie Holloway, 'I Hear Music', Loesser Genius (Q-Note, 2003)

Barry Manilow, 'Mandy', Barry Manilow II (Bell, 1974)

Barry Manilow, 'I Write the Songs', Tryin' to Get the Feeling (Arista, 1975)

Barry Manilow, 'Weekend in New England', This One’s for You (Arista, 1976)

Barry Manilow, Greatest Hits (Arista, 1978)

The Mindbenders, ‘A Groovy Kind of Love' (Fontana, 1965)

Liza Minnelli, 'Cabaret', Live at the Winter Garden (Columbia, 1974)

The Pretenders, 'Back on the Chain Gang', Learning to Crawl (Sire, 1983)

Rainbow, ‘Since You Been Gone’, Down to Earth (Polydor, 1979)

Cliff Richard, ‘Summer Holiday’ (Columbia, 1963)

The Ronettes, 'Sleigh Ride', A Christmas Gift for You from Philles Records (Philles, 1963)

Jimmy Ruffin, 'What Becomes of the Brokenhearted?’ (Motown (Soul), 1966) 
Paul Simon, Greatest Hits Etc. (Columbia, 1977)

Frank Sinatra, 'The Lady is a Tramp' (Pal Joey original soundtrack, Capitol, 1957)

Frank Sinatra, 'Ol’ MacDonald' (Capitol, 1960)

Frank Sinatra, 'I Get a Kick out of You', Sinatra and Swingin' Brass (Reprise, 1962)

Dusty Springfield, 'You Don’t Have to Say You Love Me' (Phillips, 1966)

Squeeze, 'Up the Junction', Cool for Cats (A \& M, 1979)

The Smiths, 'Paint a Vulgar Picture', Strangeways Here We Come (Rough Trade, 1987)

Bruce Springsteen, 'The Ties that Bind', The River (Columbia, 1980)

Supertramp, 'Dreamer', Crime of the Century (A and M, 1974)

Jo Stafford and Gordon MacRae, 'Abide with me’, Whispering Hope (Capitol, 1962)

Cat Stevens, 'Morning Has Broken', Teaser and the Firecat (Island, 1971)

The Tremeloes, 'Silence is Golden' (Columbia, 1967)

Conway Twitty, 'I'd Love to Lay You Down', Heart and Soul (MCA, 1980)

Bobby Vee, 'Take Good Care of My Baby’ (Liberty, 1961)

Westlife, Greatest Hits (RCA, 2011)

\section{SCORE-BASED WORKS}

W. A. Mozart, 'Voi che Sapete', Le Nozze di Figaro, K. 482 (1792)

Robert Schumann's Faschingsschwank aus Wien, op. 26 (1839) 
1 This paper has benefitted from many suggestions but I especially thank Matthew Beattie, Walter Everett, Allan F. Moore, Adam Ricci, Huw Thomas and the paper's two anonymous readers for Popular Music; Russell Davies's songbook programme on BBC Radio Two; and students on modules U66005 and U66071 at Oxford Brookes University. The paper was read to a research seminar at Bath Spa University (9.5.13), and to the Popular Music Analysis Conference at Liverpool University (3.7.13).

2 It depends upon what is meant by 'popular' music. Le Nozze di Figaro is still firmly in the repertory of many opera companies , internationally, two hundred plus years after its first performance in 1786, and 'Voi che sapete' has been performed and recorded many times, both in the context of the opera and as part of song recitals. Most so-called popular music can only dream of attaining and maintaining such popularity.

3 Bailey's original description of expressive tonality referred specifically to 'sequential melodic construction' (Bailey, p. 51): see Ricci, footnote 5, p. 130.

4 A 'parodic character' is also found in 'Stand' (along with 'Go West' by The Pet Shop Boys) by Fred E. Maus (Maus 2003, p. 556).

${ }_{5}$ Walter Everett kindly sent me his list of 'truck driver modulations' used in compiling the diagram. There were 371 examples, of which the vast majority (331) were T1. 30 were T2 with 10 examples a mixture of T3, T10, T11, and unusual cases. Of the $331 \mathrm{~T} 1$ examples, 76 were multiple modulations, more than one in the same track: 49 traversing three keys (including the first), 16 traversing four keys, 5 traversing five keys, 4 traversing six keys, and one traversing eight keys.

6 'Directions for future research might include the following: (1) an investigation into disorienting passages - modern day 'purple patches' - in the music of Chicago and in other popular music; (2) a study of the pump-up in popular music in general, with an eye to discovering other examples of a structural use of the pump-up; (3) a study of how the expressive tonality of the nineteenth century transmogrified itself into the pump-up of the mid-to-late twentieth century - is there a direct lineage, or is the connection a bit more fuzzy?; (4) and finally, a more extensive theoretical foray into the interaction between cyclic and Schenkerian structures.' (Ricci 2000, p. 146).

${ }_{7}$ For terms from languages other than English, I thank Catherine Rudent and Jebediah Sklower (French), Franco Fabbri (Italian), Barbara Eichner and Elina Hamilton (Japanese), Alf Bjornberg (Swedish), Wyn Thomas (Welsh). 8 Everett presents the 'clutch' dominant leading to the dominant of the new key a semitone higher (Everett 1997 footnote 17, p. 151): I characterize this technique below as the 'dominant handover'. Indeed, the same technique is found to represent 'truck-driver modulation' in the website supporting Everett 2009 (chapter 11, audio example 27). 
9 Ricci contrasts T1 and T2 in three ways: rhetorical weight, shift in pitch space, and change of pitch-class collection. (Ricci 2000, footnote 6, p. 131).

10 There are examples where the music patently goes down - Conway Twitty's 'I'd Love to Lay You Down' (1980) is well identified by Anwood (2003) - but I prefer the seeming neutrality of the consistent upward reference. Twitty has two tonic-tonic juxtapositions, T-2, from D to C (2’35: 78\%), and again from C to B flat (2'58: $89 \%)$, in a record that fades at 3'19.

11 I am not for a moment claiming this to be the first elevating modulation, and considerable further research and debate would be needed even to begin to make that discovery. Anwood (2003) is misguided in describing Peggy Lee's Fever (1956) as 'one of the earliest known examples'.

12 Used as the basis of a blackface scene in the film Here Come the Waves (1944), the song is presented as a more elaborate schema: Crosby starts with a solo in C, a duet with Sonny Tufts follows in F, a piano solo for dancing in Bb, back to $\mathrm{C}$ for the song as duet with chorus, before a final return to $\mathrm{F}$ as duet with chorus

13 'Dreamer' by Supertramp is a fascinating example of the drop down a tone, T10, followed by the return to tonic, T2. 2'58 sounds like an elevating modulation of sorts (the track lasts 3'30: 85\%), although the very ending of the track (3'16-18) is the pair of chords (F-G) first heard at 0'15-16, followed by a short instrumental melody (A-B-A-G-F\#-E). The elevation at 2'58 replicates one heard at 0'44, and it is the avoidance of the elevation (at 1'19) that instigates the remarkable passage from 1' 19 to $2^{\prime} 58,47 \%$ of the track as a whole. Locally, the elevation is VIIb (at 2' 46 , that is C) $\mathrm{VIIb} / \mathrm{VIIb}$ (that is, $\mathrm{Bb} / \mathrm{C}$ ), leading to $\mathrm{D}$ at 2'58.

14 'When is a modulation not a modulation?', asks Donald Francis Tovey $(1949$, p. 138), to which the usual answer is: when it's a tonicization (see for example Gauldin 1997, pp. 255 and 258). With elevating form, most examples are clear-cut, but there can be ambiguous cases. For example, Everett includes 'What Becomes of the Brokenhearted?' by Jimmy Ruffin as tonicization of II (p. 288) rather than his 'truck-driver modulation' (Everett 2009, pp. 283-4) but, at a stretch, the song could qualify as another example of a track that includes an elevation but returns to the original key. The modulation (from Bb to $\mathrm{C}$ ) heralds the song's chorus, at 'filled with sadness and confusion' (0.46 in a track lasting 2'52: 31\%, but heard a second time at the chorus's return).

${ }_{15}$ Frank Sinatra's version of the song does just that, but the resemblance ends there, Sinatra's farm consisting only of a 'chick', who turns out to be MacDonald's daughter!

${ }_{16}$ Both shifts hinge on the progression V7/vi to vi. For T10, from D to C, as at the introduction, vi of D becomes V7/IV in C (G7) with B as common-tone in bass. For T2, from C to D, V7/vi leads to vi (E7 to Am), then simply follows sequentially upwards, V7/vi to vi in D (F\#7 to Bm). 
${ }_{17}$ Bobby Darin's 'Clementine' (1960) closely followed the modulatory pattern of 'Mack the Knife'.

18 The first elevation in the track is found at 0' 35 (21\% of record), where the music veers T3 from A to C, via G at 0’33 (chord progression: A-D7-G). Thus overall, the track traverses T4, starting in A and ending in Db.

${ }_{19}$ Phil Collins's version is smoother in general, including its T2 modulation by plagals: the original tonic (G, at 1'27), D over G pedal (1'30), and then a settling onto A (1'34 of 3’28, 45\%).

20 This model is found in several examples by the band Westlife, in tracks such as 'If I Let You Go', 'My Love', 'Uptown Girl', 'Queen of My Heart', as well as their cover of Manilow's 'Mandy'.

${ }_{21}$ B is the final key, although Swann includes a passing reference to A (at 2’35-2’39) before the final cadence. 22 'I've never modulated a song in midstream. I might find a way to do it - maybe in the middle of a line except in [sic] the beginning of a verse. There might be some sneaky ways to do it.' Leonard Cohen (Zollo 1997: 342).

23 A similar example is found in I Am What I Am' recorded by Gloria Gaynor, the track has already (at 3'26) modulated $\mathrm{T} 2$ to reach $\mathrm{G}$ from an initial F, via a sudden D dominant (at 3'25), but then cuts mid-phrase to Ab (T1) (at 3'48, of 5'52: 65\%). See also the final verse of Frank Sinatra's 'I Get a Kick out of You' (T1 at 2'42 of 3'12: 84\%). 24 On this track, see Lambert (2007), p. 183, and see also the useful discussion of precedents for modulation in the Beach Boys, in the Jaguars and Four Freshmen, at pp. 30-1.

25 Aspects of the track dealt with in Metzer (2012), p. 440, exemplifying 'a wrenching modulation up a step, the cliché hallmark of the power ballad' (p. 439).

26 'Up the Junction' is one of the subset of tracks that begin and end in the same key, with a more complex passage to steer the music from $\mathrm{E}$ to $\mathrm{D}$ (at 1'31: 49\%).

27 The dominant-to-tonic juxtaposition becomes so embedded that even its absence can be noteworthy. The Rainbow cover version of 'Since You Been Gone' elevates at 2'16 of a track lasting 3'12 (70\%), as a dominant-to-tonic plagal: the passage at 2'04 ends on D as dominant of G (brief rhythmic drama, and a vocal exclamation at 2'14-6), then drops as subdominant to A as new tonic. Thus, retrospectively, in Russ Ballard's original recording, also in G major, the modulation fails to occur at exactly 1'54 of its 2'52! Celine Dion's 'The Power of Love', lasting 4'48, has an extended dominant at 3'11-8 (and even a 'whoosh' effect at 3'17) but continues resolutely in A flat major. 


\section{Diagram One}

T1
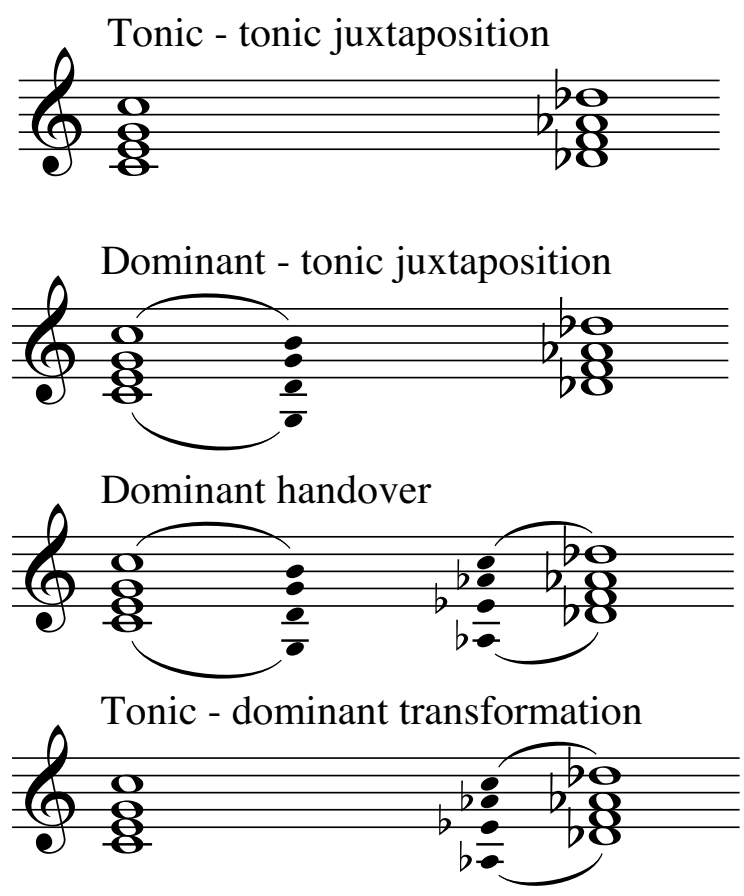


\section{Diagram Two}

T2

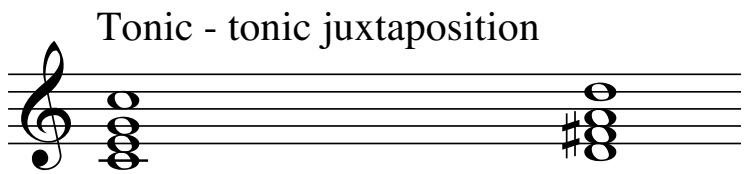

Dominant - tonic juxtaposition
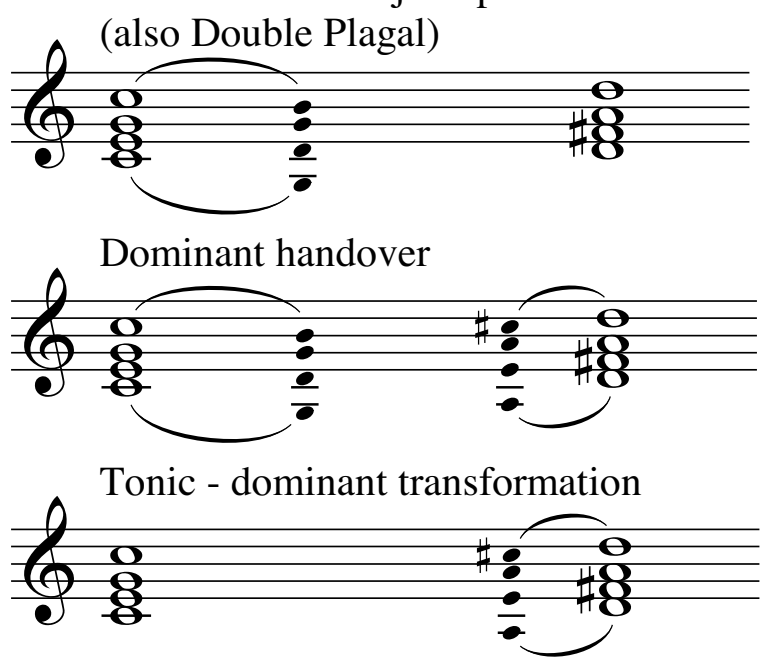
Example One

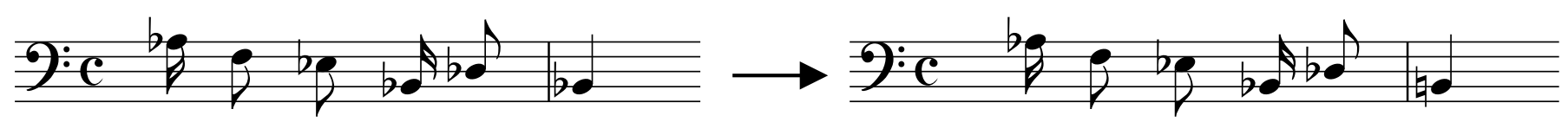




\section{Example Two}

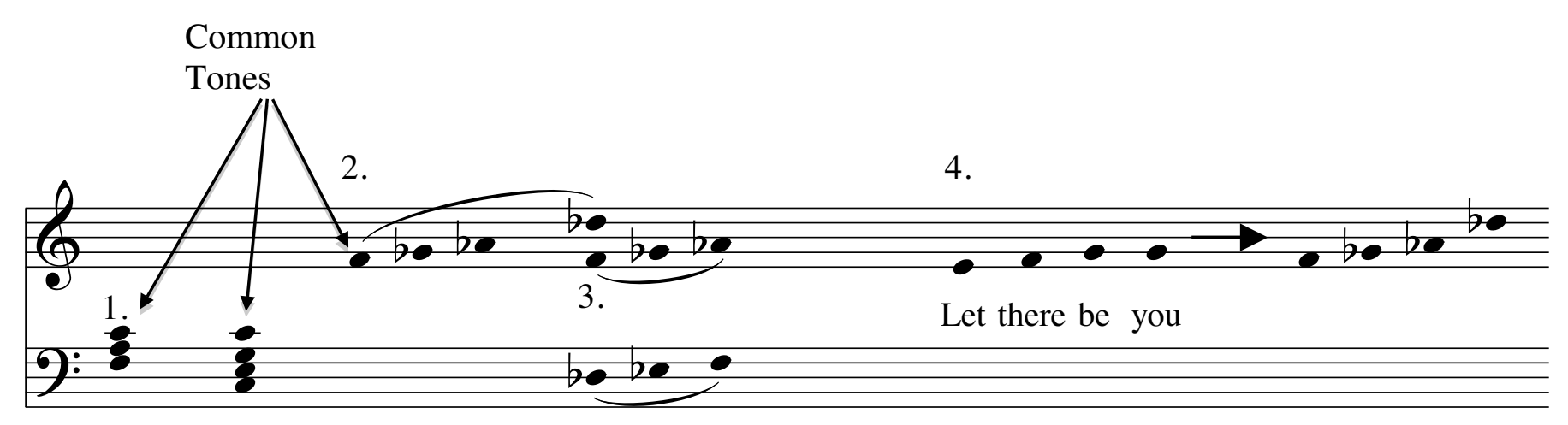


Example Three

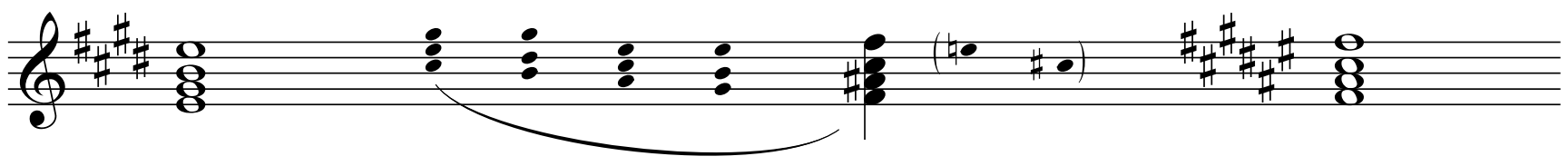




\section{Example Four}

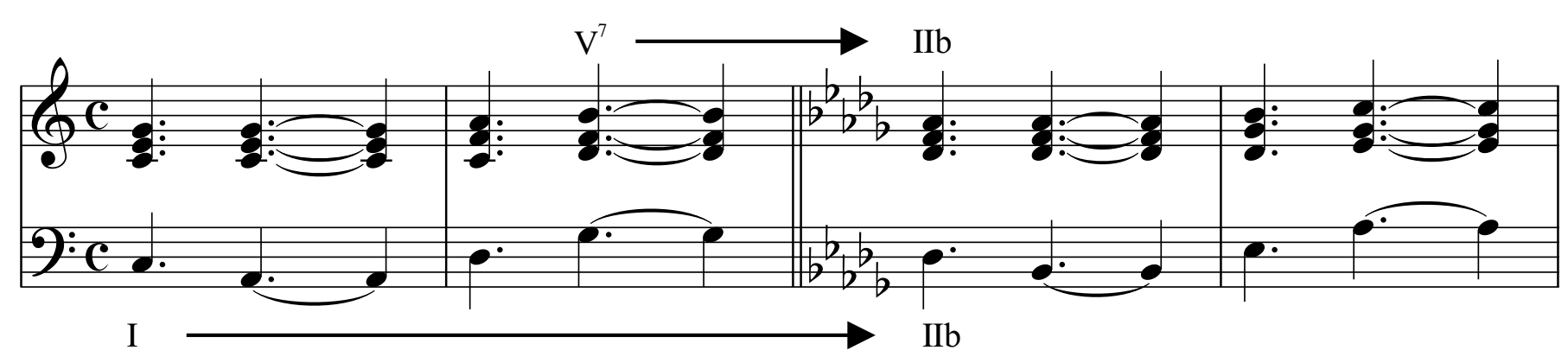




\section{Example Five}

Sings far too loud, far too of - ten and flat

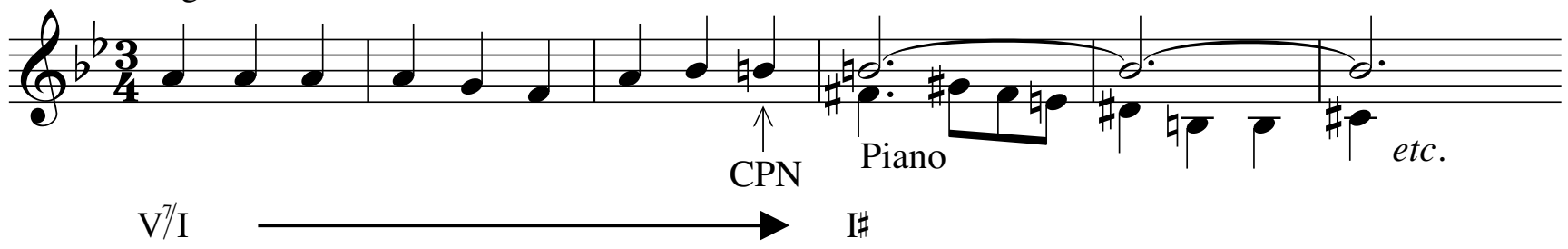




\section{Example Six}

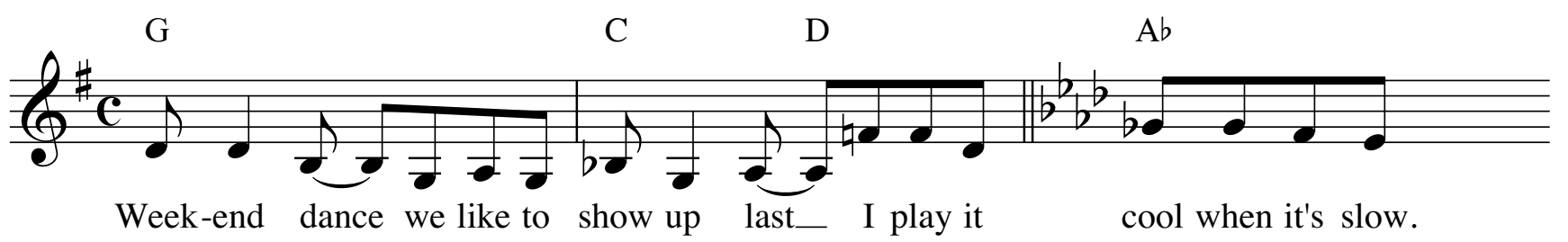


Example Seven (1)

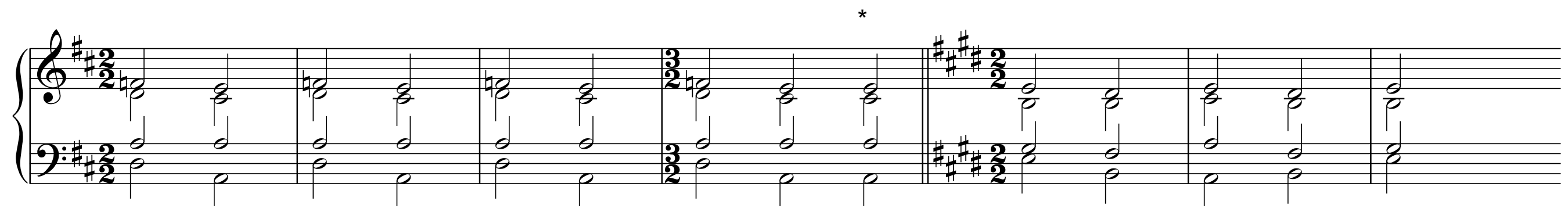


Example Seven (2)

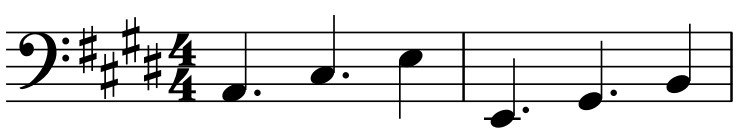




\section{Example Eight}

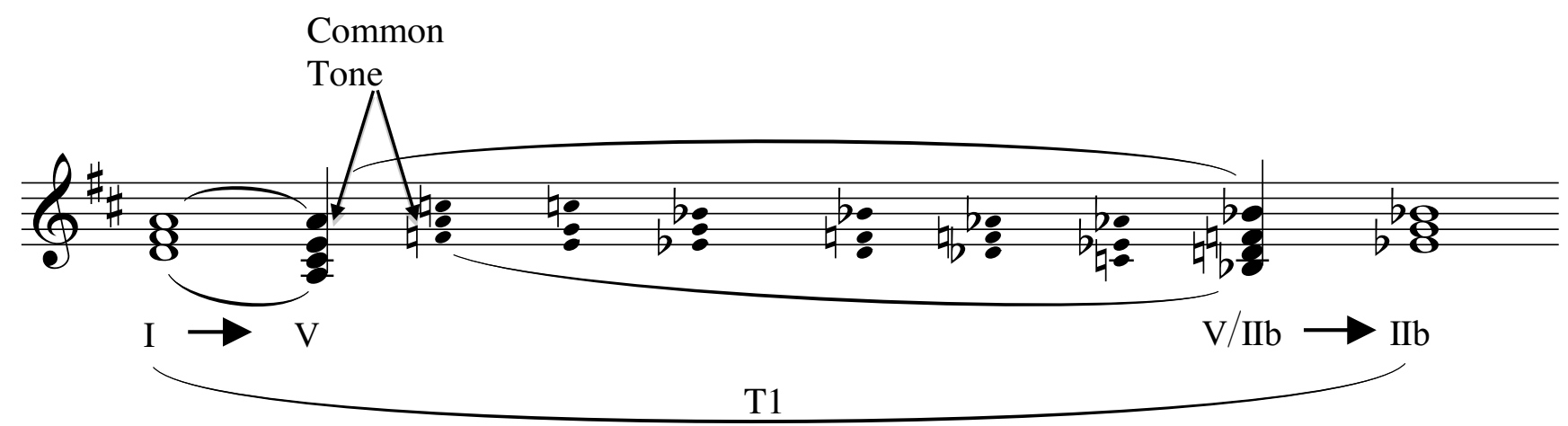


Example Nine

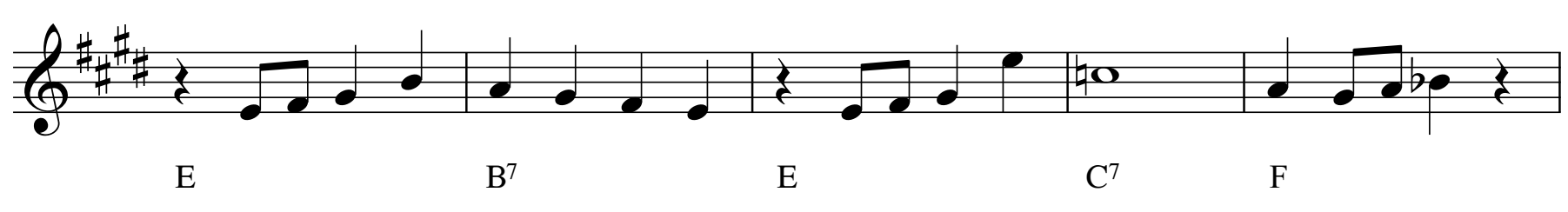


APPENDIX: Barry Manilow elevations, Greatest Hits (1978)

This table examines the 1978 collection in toto, and makes observations about modulation where relevant. It first shows percentage proportions to support a point made in the paper about elevating form. Second, it shows type of modulation for relevant tracks. Finally, under 'author notes' two points are made: the music is either composed by BM or not; second, a point is made about whether the modulation (M) is found in the published sheet music (Barry Manilow, 2000).

\section{Track/date}

Mandy 74

New York City rhythm 75

Trying to get the feeling again 74

Ready to take a chance again $77 / 78$

Looks like we made it 76

Daybreak 77 (studio version)

Can't smile without you 75

\section{It's a miracle 74}

Even now 78

Bandstand boogie 54/75

Could it be magic 73

Somewhere in the night 75

Jump shout boogie 76

Weekend in New England 76
$\mathrm{M}$

X

Time M time \%

M distance

T2: Bb-C

stays Am

stays $\mathrm{Cm} / \mathrm{Eb}$

$\mathrm{X}$

X

$x x$

XXX

187

87

$130 \quad 70$

X

207

152

73

stays $\mathrm{Ab}$

$\mathrm{T} 1: \mathrm{A}-\mathrm{Bb}$

X

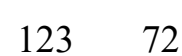

T1: A-Bb stays $\mathrm{C} / \mathrm{Cm}$

203

185

139

143

226

$175 \quad 77$

$\mathrm{T} 2: \mathrm{Bb}-\mathrm{C}$

T1: C-Db

T1: C-Db
Author notes

not BM, $\mathrm{M}$ in sheet music

music BM

Modulation type

DOMINANT-TONIC

not BM

not BM, M not in sheet music

DOMINANT-TONIC

DOMINANT-TONIC

TONIC (LOOP) - TONIC

DOMINANT HANDOVER

DOMINANT HANDOVER

DOMINANT HANDOVER

music BM

music $\mathrm{BM}, \mathrm{M}$ in sheet music

DOMINANT-TONIC

(D of $\mathrm{E} 7=\mathrm{D}$ of $\mathrm{Bb} !)$

not BM, M in sheet music

FLAT VI (of major I) $=$ V/IIb

music BM (Chopin !)

not BM, M in sheet music

music BM, M in sheet music

not $\mathrm{BM}, \mathrm{M}$ in sheet music
DOMINANT-TONIC

FLAT VI (of major I) = V/IIb

DOMINANT-TONIC 


\begin{tabular}{|c|c|c|c|c|c|c|c|}
\hline All the Time 76 & & 197 & & & stays $\mathrm{C}$ & music BM & \\
\hline This one's for you 76 & & 206 & & & stays $\mathrm{Bm} / \mathrm{D}$ & music BM & \\
\hline Copacabana (at the Copa) 78 & & 341 & & & stays Gm & music BM & \\
\hline Beautiful music 75 & & 278 & & & stays $\mathrm{C}$ & music BM & \\
\hline I write the songs 76 & $\mathrm{XX}$ & 235 & 154 & 66 & T4: F-A & not $\mathrm{BM}$, first $\mathrm{M}$ in sheet music & DOMINANT-TONIC \\
\hline & & & 179 & 76 & T2: A-B & & TONIC-DOM \\
\hline
\end{tabular}

Thus, the album had 11 elevating forms in 19 tracks: 58\% 